\title{
When to use in situ hybridization for the detection of Epstein-Barr virus: a review of Epstein-Barr virus-associated lymphomas
}

\author{
Shin-ichi Nakatsuka • Keiichirou Homma • \\ Katsuyuki Aozasa
}

Received: 15 October 2014 / Accepted: 23 December 2014 /Published online: 16 January 2015

(C) Springer-Verlag Berlin Heidelberg 2015

\begin{abstract}
Epstein-Barr (EBV) is the first virus supposed to be causative for human neoplasm. To date, list of EBV-associated lymphomas includes Burkitt lymphoma, Hodgkin lymphoma, pyothorax-associated lymphoma, primary effusion lymphoma, nasal type extranodal natural killer/T cell lymphoma, plasmablastic lymphoma, immunodeficiency-associated lymphoproliferative disorders, and lymphomatoid granulomatosis. In these diseases, presence of EBV could be detected at protein level by immunohistochemistry and at genetical level by polymerase chain reaction and in situ hybridization both applicable on routinely processed formalin-fixed, paraffinembedded specimens. Clonality of EBV-infected cells could be examined by Southern blot analysis. EBV status examined using these ancillary diagnostic tools were informative for diagnosis of lymphoma, especially diseases developing under immunodeficient condition and diseases showing polymorphous histology with or without large multinucleated cell like a Hodgkin-Reed Sternberg cell. Comprehensive evaluation of clinical presentation, histology, immunohistochemistry, genetic aberration, and EBV status enable accurate diagnosis of EBV-associated lymphoma.
\end{abstract}

Keywords Malignant lymphoma · Epstein-Barr virus · In situ hybridization · Immunodeficiency

\footnotetext{
S.-i. Nakatsuka $(\bowtie)$

Department of Pathology, Kansai Rosai Hospital, 3-1-69 Inabaso, Amagasaki 660-8511, Hyogo, Japan

e-mail: nakatsuka@kanrou.net

K. Homma

Department of Pathology, Osaka University Graduate School of Medicine, 2-2 Yamadaoka, Suita 565-0871, Osaka, Japan

K. Aozasa

Osaka University, 2-2 Yamadaoka, Suita 565-0871, Osaka, Japan
}

\section{Introduction}

Viruses are assumed to be associated with the development of malignant lymphomas, for example, Epstein-Barr virus (EBV) is associated with Burkitt lymphoma development [1, 2]. They are also assumed to be associated with lymphomas developing in immunocompromised hosts [3-5], for example, human T-lymphotropic virus type 1 has been associated with adult $\mathrm{T}$ cell leukemia/lymphoma (ATLL) [6], human herpesvirus type 8 (HHV-8) with primary effusion lymphoma (PEL) [7], hepatitis C virus with lymphoplasmacytic lymphoma [8], and simian virus 40 with diffuse large B cell lymphoma (DLBCL) [9]. Particularly, information regarding the etiological role of EBV in B cell non-Hodgkin and Hodgkin lymphoma has been collected.

Presence of EBV in lesional tissues could be shown by polymerase chain reaction (PCR) using specific primers for EBV and in situ hybridization (ISH) using EBV-encoded small RNA-1 (EBER-1) probes, which are applicable even on routinely processed, formalin-fixed, paraffin-embedded specimens (FFPE). Expression of EBV latent antigens, particularly latent membrane protein (LMP)-1 and EBV nuclear antigen (EBNA)-2, could be detected at the protein level by immunohistochemistry and at the genetic level by biochemical methods. Oncogenic role of LMP-1 and EBNA-2 is wellknown. The presence of EBV along with latent gene expression provides an insight on the substantial role of EBV in lymphomagenesis. In addition, by analyzing the fusion patterns of terminal repeats of EBV, clonality of EBV-containing cells could be determined.

The positive rate of EBV is high in several types of lymphoma [10], including Burkitt lymphoma [1, 2], lymphomas developing in immunocompromised hosts [3-5], Hodgkin lymphoma, particularly mixed cellularity subtype [11, 12], nasal-type extranodal natural killer/T cell lymphoma (ENKTL) [13-15], and pyothorax-associated lymphoma 
(PAL) [16-18]. Thus, the detection of EBV could be useful for the diagnosis of these types of lymphomas.

In this review, we will provide an overview of EBVassociated lymphomas and discuss the optimal time to test EBV status and how we can practically use this testing for diagnosing lymphomas.

\section{Epstein-Barr virus (EBV)}

Burkitt lymphoma is a lymphoid neoplasm; it was first described as a round cell sarcoma by Dennis Burkitt in 1958 and was observed to develop in the jaw or abdominal cavity of a child [19]. In 1964, Anthony Epstein and Ivonne Barr discovered a herpesvirus-like particle in the cytoplasm of the cell line established from biopsy samples of a patient with Burkitt lymphoma [1]. This new member of the herpesvirus family was first named as human herpesvirus-4 and subsequently termed as "EBV." It comprised approximately $170 \mathrm{kbp}$ of double-stranded DNA. Various viral products, including some proteins that are expressed during latent infection, such as LMP-1 and LMP-2 and EBNA-1, EBNA-2, and EBNA-3, are encoded in either sense or antisense chains. EBV infects B lymphocytes through the pharyngeal epithelium. Most (more than $90 \%$ ) of the viruses establish latent infection, expressing a subset of viral latent genes, and reside in B lymphocytes throughout the life of the host. A few of the viruses enter via lytic infection and replicate, but subsequently, they get eliminated by the immune system of the host. Therefore, many people are transiently infected with EBV and either show non-specific symptoms similar to common cold or no symptoms for the first few years of their lives. It is notable that in well-developed countries, where people live in a hygienic environment, primary infection is more frequently delayed until adolescence or adulthood. Thus, people with primary EBV infection may develop infectious mononucleosis (IM).

EBV is the first virus that was elucidated to be a possible causative agent for human neoplasm $[1,2,10]$. To date, EBV has been demonstrated to be associated with Hodgkin lymphoma [11, 12], nasal-type ENKTL [13-15], PAL [16-18], and immunodeficiency-associated lymphoproliferative disorders [3-5]. In the updated World Health Organization (WHO) classification, 15 diseases are listed as EBV-associated lymphoproliferative disorders [20] (Table 1). Other than lymphoid neoplasms, it has been shown that EBV is related to nasopharyngeal carcinoma, a variant of gastric cancer accompanied with characteristic lymphoid stroma, and some forms of mesenchymal neoplasms [21, 22].

EBV is present as a latent infection in the majority of EBVpositive lymphoma cells. In very few cells (less than $1 \%$ of the total number of tumor cells), EBV infection enters through the lytic phase. EBV BZLF1 and BRLF1 proteins play a key
Table 1 List of EBV-associated lymphomas (WHO classification, 2008)

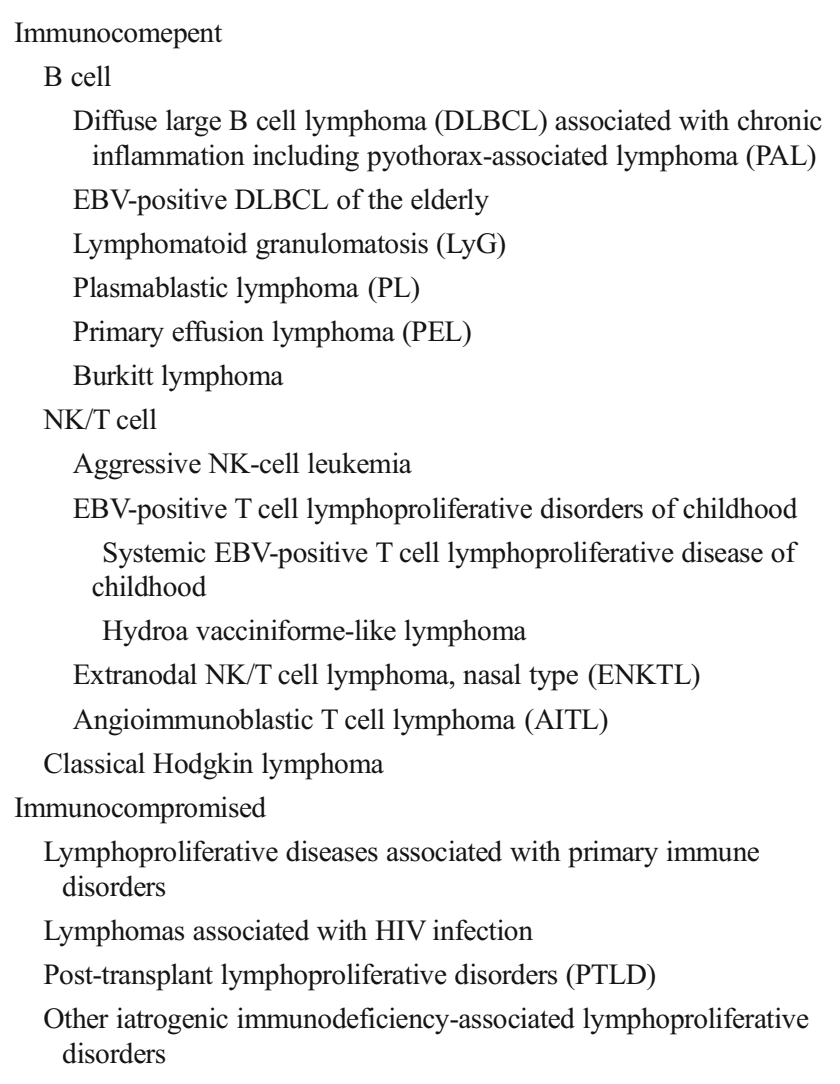

role in the transition from latent to lytic infection. Lymphoma cells, in which EBV switches from latent to lytic infection, produce viral particles and secrete various cytokines. They may also promote proliferation of tumor cells via a paracrine mechanism. A recent study showed that IL-13 that is induced by BZLF protein suppresses cytotoxic $\mathrm{T}$ cells and augments the efficiency of transformation of EBV-infected B lymphocytes [23].

There are three types of latent infections of EBV, which are classified according to the expression pattern of latencyassociated proteins. EBV-associated neoplasms show different types of latent infections (Table 2). Most of the latencyassociated proteins have antigenicity recognized by the immune system of the host. These findings suggest that the immune reaction of the host to tumor cells infected with EBV and the oncogenic role of EBV differ among various EBVassociated neoplasms.

Recently, the role of micro RNAs (miRNAs) encoded by the EBV genome in the pathogenesis of EBV-positive lymphomas has been investigated. The miRNAs of EBV are encoded as a cluster at the BHRF and BART gene regions. They interact with the cellular processes of hosts and alter the state of viral infection, innate immunity, cell survival, and cell proliferation. BART miRNA suppresses apoptosis through 
Table 2 Manners of EBV latent infection accoding to expression of latency-associated viral products

\begin{tabular}{llllllll}
\hline Manner of latent infection & EBER & EBNA-1 & EBNA-2 & EBNA-3 & LMP-1 & LMP-2 & Type of lymphoma \\
\hline Latency I & + & + & - & - & - & - & Burkitt lymphoma, PEL, PL \\
Latancy II & + & + & - & - & + & + & Hodgkin lymphoma, ENKTL, LyG \\
Latency III & + & + & + & + & + & + & PAL, immunodeficiency-associated \\
& & & & & & &
\end{tabular}

EBER EBV-encode small RNA, ENBA EBV nuclear antigen, $L M P$ latent membrane protein, $P E L$ primary effusion lymphoma, $P L$ plasmablastic lymphoma, ENKTL extranodal NK/T cell lymphoma, $L y G$ lymphomatoid granulomatosis, $P A L$ pyothorax-associated lymphoma

upregulation of the p53 upregulated modulator of apoptosis and downregulation of CASP3, a pro-apoptotic transcript [24, 25]. BHRF1 miRNA suppresses expression of CXCL-11, an interferon-inducible chemokine and T cell attractant, which contributes to evasion of EBV-infected tumor cells by immunosurveillance of the host [26]. BART miRNA are expressed in each state of latency, and BART miRNA and BHRF1 are expressed in all EBV-positive PTLD [27], suggesting a significant role of the viral miRNAs of EBV in the etiology of EBV-positive lymphomas.

\section{Detection methods for EBV}

Immunohistochemical methods enable the detection of proteins associated with EBV latent infection, such as EBNA-2 and LMP-1. Immunohistochemistry for EBNA-2 and LMP-1 is a versatile and easy-to-use method for detection of FFPE, although its specificity is inferior to PCR and its ambiguity in evaluation of the results and inter- or intra-observer variability may be problematic.

PCR is a sensitive method for detection of EBV. During practical use, however, this method requires careful attention to avoid contamination of EBV nucleic acids among individual samples or contamination of EBV from the saliva of examiners, as EBV ubiquitously infects majority of the population. Nucleic acids extracted from FFPE can be used for detection by PCR, although it is required to bear in mind that degeneration of the extracted nucleic acids may result in falsenegatives.

ISH detects EBER-1 that is expressed during the latent infection. This technique has the advantage that latent infection of EBV in tumor cells can be visible in situ on histological sections. Because large copy numbers of EBER-1 are expressed in the infected cells, degeneration of mRNA in FFPE is negligible pertaining to the sensitivity of this detection method. Thus, EBER-1 ISH is widely recommended for detection of EBV. Detection kits for EBV using ISH are provided commercially, and some of them are applicable to automated staining machines; therefore, there are no technical obstacles in the practical use of ISH in the laboratories of community hospitals.

Southern blot analysis is a method that is useful to evaluate clonality of EBV infected cells in tumor tissues. EBV DNA exists in a linear form in viral particles, which converts to a circulated episomal form in host cells during viral infections. There are sequences named as terminal repeats at both ends of the linear form of EBV DNA. The terminal repeats on both ends fuse when the virus takes its episomal form. Because each EBV particle has DNA with a unique copy number in terminal repeats, digestion by restriction enzymes generates the proper length of digested DNA fragment. Electrophoretical fractioning of enzymatic digests enables assessment of the clonality of infected EBV population in the lesional tissue. Southern blot procedures require technical skills; therefore, this test can only be performed in wellequipped research laboratories.

\section{Infectious mononucleosis (IM)}

IM is an acute infectious disease that is caused by an EBV primary infection. Its symptoms include fever, pharyngitis, cervical lymphadenopathy, and, less frequently, hepatomegaly with liver dysfunction, splenomegaly, and systemic lymphadenopathy. Hematological findings are leukocytosis and lymphocytosis with atypical lymphocytes, also known as Downey cells. Antibodies against EBV (viral capsid antigenIg M, antigen-Ig G, and early antigen-Ig G) are elevated in the acute phase. Diagnosis of IM does not require histological evaluation of the biopsied lymph nodes, because clinical presentation and hematological and serological findings are usually enough for its definitive diagnosis. Histologically, lymph node architecture is largely preserved, but it is partially effaced with paracortex hyperplasia and focal necrosis. Cellular components of the paracortex are polymorphous, including various sized lymphocytes, immunoblasts, macrophages, plasma cells, and eosinophils. Sometimes sheets of immunoblast proliferation mimic large cell lymphoma. Large polynucleated cells, resembling Hodgkin-Reed Sternberg cells (HRS) cells, 
are also observed. EBER-ISH shows many EBV-infected large lymphoid cells within affected lymph nodes.

\section{Burkitt lymphoma}

Burkitt lymphoma is the first human neoplasm demonstrated to be associated with viral infection $[1,2,10]$, although EBV is no longer believed to be a unique essential pathogen of this disease. Burkitt lymphoma is divided into three subtypes according to clinicopathological characteristics: endemic, sporadic, and immunodeficiency-associated type [2, 28]. Detection rate of EBV in tumor tissues varies among these variants, with nearly 100,30 , and $30 \%$ of endemic type, sporadic type, and immunodeficiency-associated type, respectively [2, 28]. This suggests that EBV has different associations with oncogenesis among these subtypes. Endemic type has been shown to be a polymicrobial disease [29]. A hypothesis has been proposed that activation of B cells by Plasmodium falciparum and the induction of activation-induced cytidine deaminase (AID) through Toll-like receptor-9 promoter translocation of the MYC gene provides a proliferative advantage in tumor cells [29-31]. Induction of AIDs by HIV is also assumed in HIV-associated Burkitt lymphoma.

Detection rate of EBV in sporadic subtypes and immunodeficiency-associated subtypes is low; therefore, detection of EBV is not crucial in establishing a diagnosis for these types. In patients with systemic immunodeficiency, EBV-associated lymphoma other than Burkitt lymphoma can also evolve; therefore, EBV status alone is not enough for the diagnosis of immunodeficiency-associated type Burkitt lymphoma. Histological and cytomorphological findings of tumor cells, immunophenotype (CD10-positive, bcl-6 positive, bcl-2 negative), and detection of MYC gene translocation by fluorescent in situ hybridization are prerequisites for the diagnosis of Burkitt lymphoma.

\section{Hodgkin lymphoma}

Association between Hodgkin lymphoma and EBV has been speculated by epidemiological studies. The prevalence of Hodgkin lymphoma is significantly higher in people with a history of IM and elevated serum levels of antibodies against EBV [32, 33]. Subsequent studies have revealed that the frequency of EBV depends on age, environmental factors such as country and socioeconomical status, and histology. Detection rate of EBV is high at the unimodal peak of disease incidence during childhood in developing countries with low socioeconomical status, and in the elderly bimodal peak in well-developed countries [12]. According to histological subtypes, detection rate is high in mixed cellularity and lymphocyte depletion type, and low in lymphocyte-rich and nodular sclerosis type [11, 12, 34].
These findings suggest that oncogenic mechanisms differ between each histological subtype of Hodgkin lymphoma. Alternatively, histological subtypes might correspond to different stages in the stepwise development of Hodgkin lymphoma. Almost all cases with nodular lymphocyte predominant type have no association with EBV [34].

Immunohistochemistry and ISH detect products of EBV latent infection in HRS cells (Fig. 1). Southern blot analysis demonstrates a monoclonal fusion pattern of the EBV genome in the tumor tissues of Hodgkin lymphoma, suggesting that EBV is involved in the early oncogenic process of this disease $[35,36]$.

Diagnosis of Hodgkin lymphoma should be based on the histological findings of hematoxylin-eosin)-stained specimen. Examination of EBV status is not always essential for diagnosis of Hodgkin lymphoma. In some conditions, detection of EBV is helpful to differentiate Hodgkin lymphoma from diseases mimicking the histological features of Hodgkin lymphoma. First, EBV status provides valuable information for differentiation of Hodgkin lymphoma from anaplastic large cell lymphoma (ALCL). It might be problematic to differentiate lymphocyte depletion subtype of Hodgkin lymphoma from ALCL because CD30-positive large pleomorphic cells appear in both diseases. Usually, EBV is not detectable in ALCL [37]; therefore, demonstration of EBV in large pleomorphic cells suggests a diagnosis of Hodgkin lymphoma. Second, detection of EBV is informative for differentiation between Hodgkin lymphoma and primary mediastinal large B cell lymphoma (PMLBCL). PMLBCL and nodular sclerosis type of Hodgkin lymphoma (NSHL) share common clinicopathological characteristics; both PMLBCL and NSHL preferentially affect young females and often arise from the

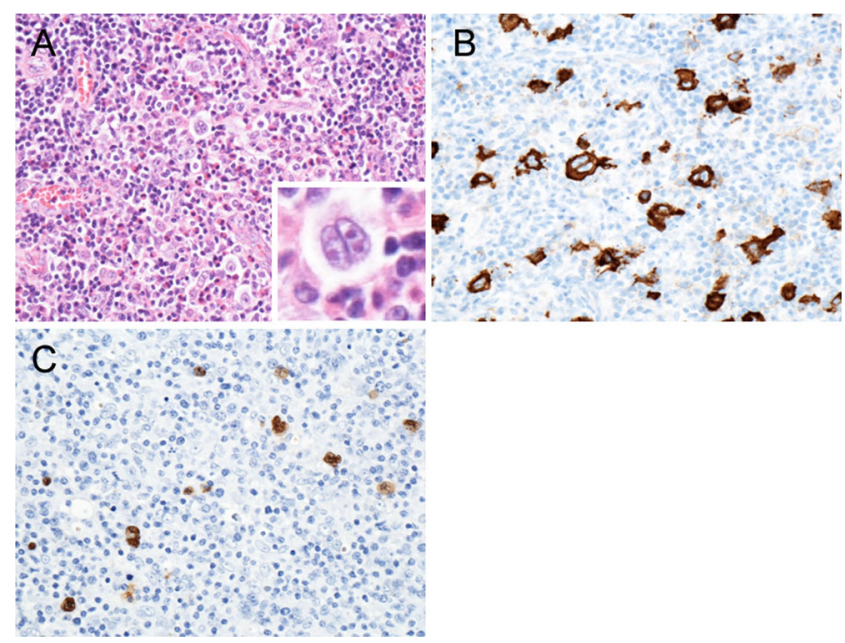

Fig. 1 Histology of Hodgkin lymphoma and detection of EBV in HRS cells by EBER-1 ISH. The histological representation of classical Hodgkin lymphoma shows scattered large atypical cells with prominent nucleolus and perinuclear halo, including typical binucleated HRS cells (inset). These cells are admixed with small lymphocytes, eosinophils, macrophages, and plasma cells (a). The large atypical cells are positive for CD30 (b) EBER-1 ISH analysis is positive in large atypical cells (c) 
mediastinum. Both tumors show a marked sclerosis in histology. Latent infection of EBV is demonstrated in NSHL, albeit at lower frequency than in lymphocyte depletion and mixed cellularity subtypes. EBV is rarely detected in PMLBCL [38]. Presence of EBV in tumor cells suggests a diagnosis of Hodgkin lymphoma, although comprehensive evaluation of clinicopathological features, including immunophenotype of tumor cells, is necessary for the definitive diagnosis. Cases showing intermediate histological features between Hodgkin lymphoma and PMLBCL are categorized as intermediate lymphoma in the WHO classification and EBV is detected in up to $20 \%$ of these cases [39].

\section{Pyothorax-associated lymphoma (PAL) and primary effusion lymphoma (PEL)}

PAL was firstly described by Aozasa et al. as a distinct clinicopathologic entity [40]. PAL is a B cell lymphoma that primarily develops from the pleura or chest wall following history of a long-standing pyothorax of more than 20 years [16, 17]. Most of the patients with PAL have a history of artificial pneumothorax for treatment of lung tuberculosis or tuberculous pleuritis. Histologically, PAL is DLBCL and usually EBV is detected in tumor cells (Fig. 2) [16-18]. Because PAL has a distinctive clinical background, in combination with DLBCL histology, demonstration of latent infection of EBV is not a prerequisite for its diagnosis. Diagnosis of PAL requires that the tumor develops during a chronic inflammatory condition of the pleural cavity $[16,17]$.

PEL is a body cavity-based disease similar to PAL. Patients with PEL present with effusion fluids in the pleural cavity,

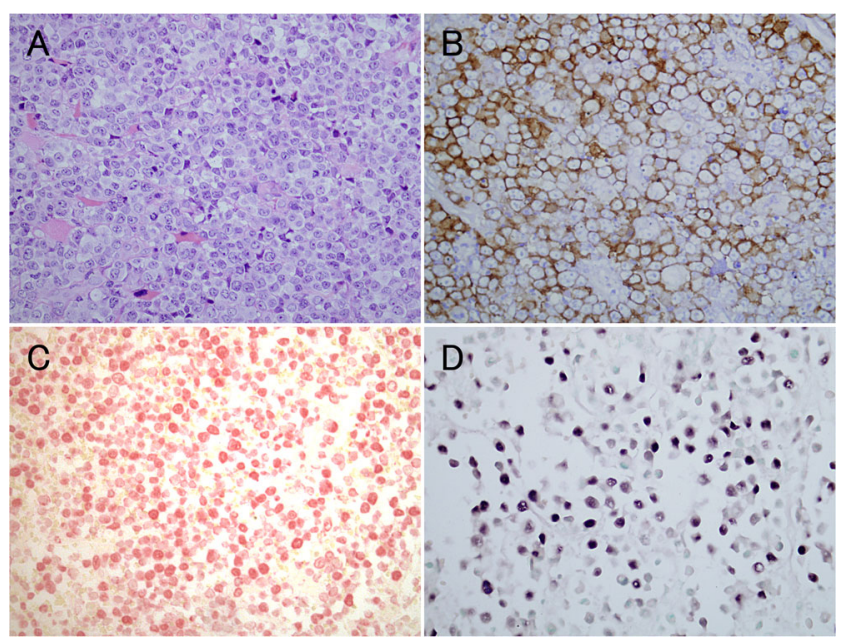

Fig. 2 Histology of PAL and detection of EBV by EBER-1 ISH. The photomicrograph shows diffuse proliferation of large lymphoid cells with irregular nuclear contour, fine chromatin, and one to several prominent nucleoli (a). These cells are positive for CD20 (b) and LMP-1 (c). EBV RNA present in the large lymphoid cell nuclei are detected by EBER-1 ISH (d) abdominal cavity, or pericardial space, usually without mass formation. HHV-8 can be detected in tumor cells floating in the effusion fluid in almost all cases [7]. Most PEL cases have a co-infection with HHV-8 and EBV [7]. Cytomorphologically, tumor cells show marked differentiation into plasma cells, thus lacking expression of CD20. PEL patients are usually affected by systemic immunodeficiency. For diagnosis of PEL, detection of HHV-8 but not $\mathrm{EBV}$ is essential, although distinctive clinical appearance and histology enable diagnosis of PEL in most cases.

\section{Extranodal NK/T cell lymphoma (ENKTL)}

ENKTL can be divided into two subtypes according to their clinical presentation. A tumor arises within the upper respiratory tract, mainly nasal cavity, in nasal type and in extranasal regions such as intestine and testis, in non-nasal type. Nasaltype ENKTL preferentially affects the facial midline area forming a necrotic tumorous lesion. Similar conditions are identified in carcinomas, syphilis, tuberculosis, and Wegener's granulomatosis. All of these diseases have been fatal in the past and are termed as lethal midline granulomas. In $1987, \mathrm{Ng}$ et al. first reported that this neoplasm expresses NK-cell marker, suggesting an NK-cell-origin [41], and subsequently molecular studies, including gene rearrangement study of T cell receptor genes, have established ENKTL as a unique disease entity [14, 15, 42]. ENKTL is prevalent in East Asia and Latin America, where Mongolid is the dominant ethnicity [43]. Histologically, medium- to large-sized lymphoid cells accompanied with inflammatory cells proliferate, showing polymorphous appearance. Polymorphous histology often makes it difficult to differentiate ENKTL from inflammatory conditions purely on morphological grounds, but immunohistochemical procedures provide a direct evidence for proliferation of NK-cells and/or T cells. Massive tumor necrosis and preferential invasion of tumor cells into vascular walls (angiocentric pattern) are also characteristic and suggestive of ENKTL. EBV is detected in more than $90 \%$ of the cases with ENKTL (Fig. 3) [14, 15]. When interpretation of immunohistochemical findings is equivocal, EBV status and results of T cell receptor gene rearrangement analysis could provide a fundamental basis for diagnosis of ENKTL. There are other types of lymphoid neoplasms and some non-neoplastic lesions that arise from the nasal cavity. Therefore, it is meaningful to differentiate ENKTL, which requires more aggressive therapy with a combination of cytotoxic agents and irradiation, from other lymphoid neoplasms such as DLBCL that are usually treated with standard chemotherapy. A recent study demonstrated that the copy number of EBV DNA in peripheral blood of ENKTL patients correlates with the disease activity and that its evaluation is useful for prediction of poor prognosis. 


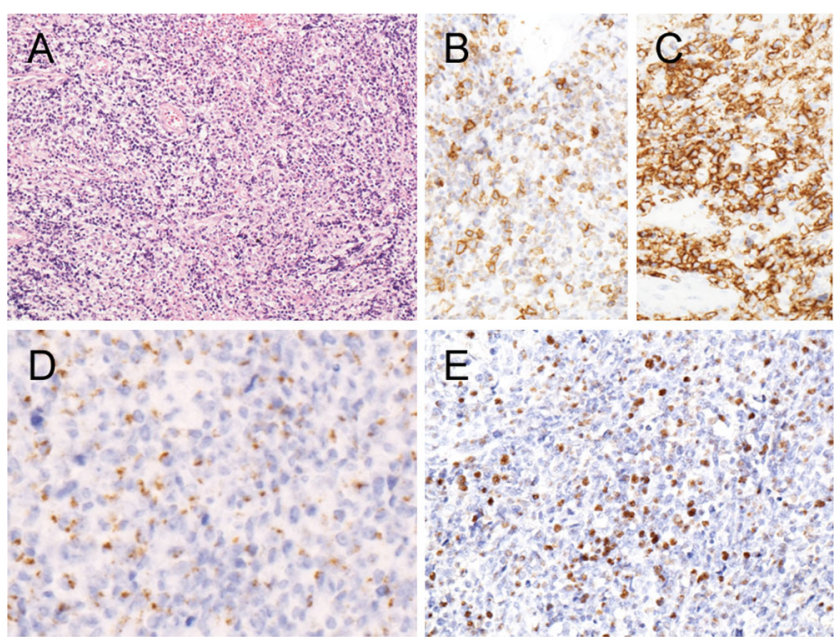

Fig. 3 Histology of ENKTL and detection of EBV by EBER-1 ISH. The lesion shows proliferation of medium-sized lymphoid cells with abundant pale cytoplasm and irregular nuclear borders, admixed with small lymphoid cells (a). These cells are positive for CD3 (b), CD56 (c), and TIA-1 (d). EBER-1 ISH analysis of nuclei is positive (e)

\section{Plasmablastic lymphoma (PL)}

Plasmablastic lymphoma (PL) is a clinically aggressive B cell lymphoma with plasmacytic differentiation that arises from the oronasal mucosa. It typically occurs with systemic immunodeficiency [44, 45]. Histologically, PL shows a diffuse proliferation of immunoblast-like cells with expression of plasmacytic markers such as CD38, CD138, and MUM-1. Tumor cells often lack CD20 expression and sometimes express CD56, and therefore, should be carefully differentiated from ENKTL. PL has high proliferative activity, i.e., high Ki67 labeling index. EBER-1 ISH detects EBV in 60-75\% of cases with PL, and almost all cases are HIV-positive [44, 45]. Combined clinicopathological findings and results of immunohistochemistry are usually adequate enough to diagnose PL; therefore, testing of EBV status is not essential. PL less commonly develops in extraoral locations of HIV-negative elderly patients $[46,47]$. It should be kept in mind that EBV positive rate is relatively low in patients with HIV-negative PL. EBV status is also valuable information for differentiation of PL from extramedullary plasmacytoma, with or without blastic transformation [46].

\section{Immunodeficiency-associated lymphoproliferative disorders}

Immunodeficiency-associated lymphoproliferative disorders include the following: (1) lymphoproliferative diseases associated with primary immune disorders, (2) lymphomas associated with HIV infection, (3) post-transplant lymphoproliferative disorders (PTLD), and (4) other iatrogenic immunodeficiencyassociated lymphoproliferative disorders [3-5, 10, 20]. EBV might have an oncogenic role in all these disorders. These disorders have various histological features of lymphoma and lymphoproliferative disorders, with polyclonal to oligoclonal lymphoid populations. Immunodeficiency-associated lymphoproliferative disorders are mostly derived from B cells, but $\mathrm{T}$ cell or NK-cell proliferation is occasional (10-15\%). Because serum anti-EBV antibody tests are negative prior to transplantation in most cases with PTLD, it has been suggested that primary EBV infection after transplantation underlies development of PTLD. Infection of EBV may occur via passenger EBV-positive lymphocytes of the organ donor or via casual exposure as occurring in immunocompetent individuals incommunity. Positive rate of EBV varies among the histological types of lymphoma. EBV is detected in more than $90 \%$ of the cases with B-PTLD and in more than $70 \%$ of the cases with T-PTLD [10]. EBV is detected in almost all cases with Hodgkin lymphoma, oral type plasmablastic lymphoma, and primary central nervous lymphoma in HIV-positive patients [4, 10]. Positve rate of EBV is relatively lower in HIV-associated Burkitt lymphoma and other iatrogenic immunodeficiency-associated lymphoproliferative disorders $[4,5,10]$.

Detection of EBV provides an important clue in the diagnosis of B-lymphoproliferative lesions with polymorphous histology, developing under immunodeficiency, because differentiation of this lesion from inflammatory lesions based on morphology is often difficult (Fig. 4). As positive signals in large neoplastic lymphocytes are revealed frequently by EBER-1 ISH, it suggests immunodeficiency-associated lymphoproliferative disorders, but definitive diagnosis often requires demonstration of tumor cells monoclonality. In cases with Hodgkin-like histology in immunodeficient individuals,

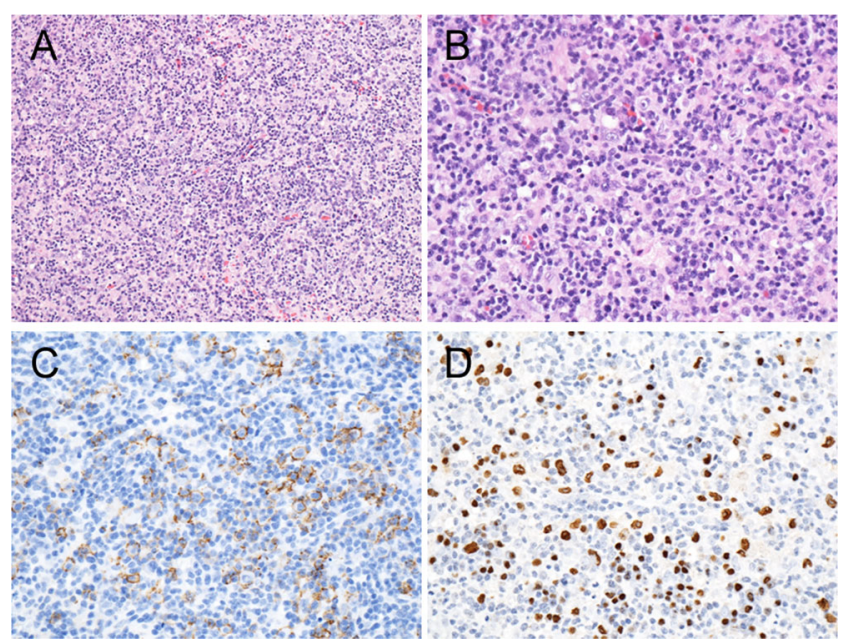

Fig. 4 Histology of polymorphous B cell lymphoma that develops under immunodeficiency and detection of EBV by EBER-1 ISH. The lesion shows mixed proliferation of small lymphoid cells, plasma cells, and medium to large lymphoid cells with bizarre nuclei (a). Bizarre large lymphoid cells are evident in the interfollicular area (b). These cells are positive for $\mathrm{CD} 20(\mathbf{c})$, and EBV RNA present in the nuclei are detected by EBER-1 ISH (d) 
presence of EBV indicates a diagnosis of lymphoma rather than non-neoplastic inflammatory changes. Growing number of cases of EBV-negative PTLD have been described, particularly, in adult solid organ transplant recipients [3]. Duration between organ transplant and development of PTLD is longer in EBV-negative cases (more than 5 years after transplant) than EBV-positive cases.

To summarize, it is desirable to test EBV status together with gene rearrangement analysis in cases of lymphoproliferative lesions, developing under systemic immunodeficient conditions, because it is often problematic to differentiate lymphoproliferative disorders from non-neoplastic inflammatory lesions. Copy number of serum EBV DNA is a marker for activity of EBV infection and serves as a useful reference for early diagnosis and prediction of disease progression [48].

\section{Others}

Lymphomatoid granulomatosis (LyG) is a rare extranodal B cell lymphoma preferentially affecting the lower respiratory tract, and it also involves the brain, kidney, liver, and skin. LyG shows a polymorphous histology, with a mixture of large or small lymphocytes, plasma cells, and macrophages, often mistaken as inflammatory lesions. Angiocentric pattern of proliferation and formation of granulomatous lesion in skin are characteristic. EBV is detected in almost all cases with LyG. Histological grade based on the number of large B cells, which are positive by EBER-1 ISH, was proposed [49]. Their histological grade is strongly correlated with their response to chemotherapy and prognosis; therefore, detection of EBV by ISH is essential for diagnosis and therapeutic decision making in LyG.

Some investigators have reported that EBV-positive B cell lymphoma, developing in elderly people, 50 years of age and older, could be categorized as a lymphoma type that is histologically similar to common type of DLBCL, although polymorphous histology accompanied with various inflammatory cells is found not infrequently. An unfavorable prognosis has been suggested in these cases as compared with the EBVnegative DLBCL. However, other investigators reported a similar prognosis with either EBV-positive or EBV-negative DLBCL [50].

Systemic EBV-positive T cell lymphoproliferative disease of childhood shows a fulminant clinical course, usually complicated by hemophagocytic syndrome, disseminate intravascular coagulopathy, and multiple organ dysfunction syndrome. These diseases are often associated with chronic active EBV infection, showing a clonal expansion of CD8positive cytotoxic $\mathrm{T}$ cells infected with EBV. Histologically, infiltration of EBV-positive, CD8-positive lymphocytes, in combination with hemophagocytic figures, is observed in the liver, spleen, and lymph nodes. Monoclonal rearrangement of $\mathrm{T}$ cell receptor genes has been detected. Hydroa vacciniforme-like lymphoma is a rare form of primary cutaneous $\mathrm{T}$ cell lymphoma in children, often associated with hypersensitivity to sunlight exposure or mosquito bites. $\mathrm{Cu}$ taneous infiltration of EBV-positive neoplastic T cells, with cytotoxic phenotype, proven to be monoclonal by rearrangement study of TCR genes is observed. Although its clinical course and prognosis are variable, systemic disease shows a more aggressive course.

In cases with angioimmunoblastic $\mathrm{T}$ cell lymphoma (AITL), ATLL, and peripheral T cell lymphoma, not otherwise specified, EBV-positive B cell population can clonally expand under severe immunodeficiency due to either progression of tumor or intensive chemotherapy [51-53]. Previous reports have shown that clonal rearrangement of immunoglobulin heavy chain genes is detected in $25-30 \%$ of AITL cases $[54,55]$. Clonal expansion of B cells in T cell lymphomas sometimes progresses to secondary B cell lymphoma, with or without EBV latent infection (Fig. 5). Alternatively, an EBV-positive B cell lymphoma may newly develop after regression of primary $\mathrm{T}$ cell lymphoma. Therefore, it is necessary to test EBV status and examine the clonality of lymphoid cells, when clinical appearance and/or histology is altered in patients with $\mathrm{T}$ cell lymphoma, without being confined to primary diagnosis.

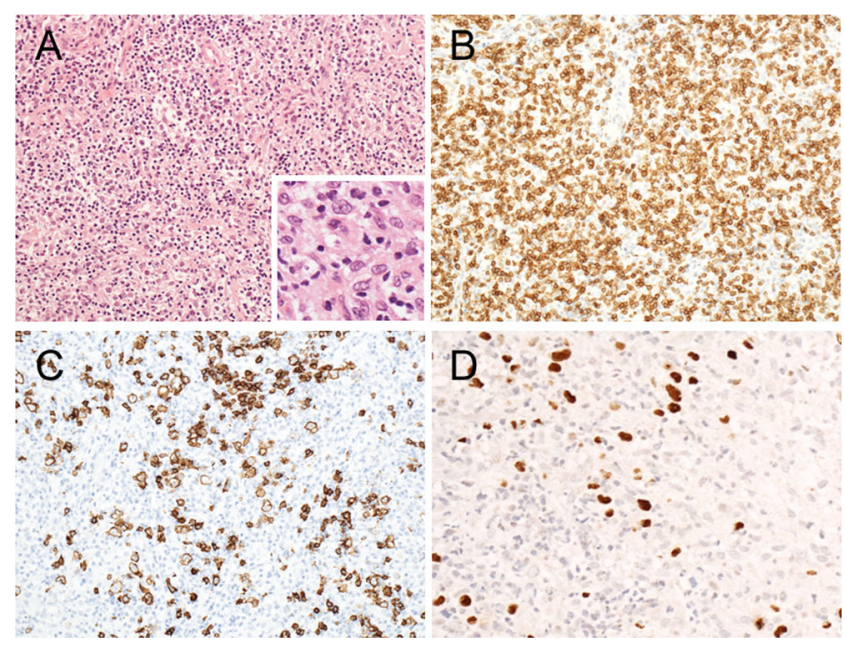

Fig. 5 Evolution of secondary B cell lymphoma in case of AITL and detection of EBV by EBER-1 ISH. The photomicrograph shows proliferation of medium-sized lymphoid cells with abundant clear cytoplasm, admixed with an inflammatory background of small lymphocytes, plasma cells, and prominent arborizing blood vessels (high endothelial venules). In addition, large lymphoid cells with bizarre nuclei are also visible throughout the lesion (inset) (a). The medium-sized lymphoid cells with clear cytoplasm are positive for CD3 (b). The large lymphoid cells with bizarre nuclei are positive for CD20 (c), and EBER-1 ISH shows positive signal in nuclei $(\mathbf{d})$ 


\section{Conclusion}

In individuals with possible immunosuppression, evaluation of EBV in lesional tissues might provide an insight into diagnosis and therapeutic modalities. Pathologists could use EBER-1 ISH as an ancillary diagnostic tool, in combination with comprehensive evaluation of the clinicopathological features of the aforementioned diseases. Alternatively, even if the immunological condition in patients is unknown, association of EBV is suspected in tumors with histological features such as lymphoma with large multinucleated cells similar to HRS cells and B cell lymphoma with polymorphous histology. Therefore, the evaluation of EBV status by ISH and information of immunological condition in patients are useful strategies for establishing diagnosis in cases with such histological features.

The number of immunocompromised patients is increasing because the progress in chemotherapy and molecular targeted drug therapy and advanced medical intervention, such as organ transplantation, may induce immunosuppression. In addition, the society is rapidly aging worldwide, and populations with underlying immunodeficiencies are believed to be growing steadily. Under such epidemiological circumstances, pathologists will have a greater opportunity to encounter EBVassociated lymphomas hereafter. There is no evidence whether different therapeutic strategies for lymphomas should be employed depending on the EBV status; thus, at present, EBV status does not have a significant impact on clinical and therapeutic approaches in any histological subtypes of lymphoma. However, it is important to differentiate certain types of aggressive lymphomas associated with EBV (e.g., ENKTL and plasmablastic lymphoma), which require more intensive therapy than that required by the common type of lymphoma such as EBV-negative DLBCL, in order to avoid inadequate treatment. In cases with iatrogenic immunodeficiency-associated lymphoproliferative disorders, withdrawal of causal agents for immunosuppression could result in remission of tumors; therefore, pathological diagnosis of EBV-associated lymphoma is advantageous in preventing excessive medical intervention by chemotherapy.

Acknowledgments The authors would like to thank Enago (www. enago.jp) for the English language review.

Conflict of interest The authors declare that they have no conflicts of interest.

\section{References}

1. Epstein MA, Achong BG, Barr YM (1964) Virus particles in cultured lymphoblasts from Burkitt's lymphoma. Lancet 1:702-703

2. Molyneux EM, Rochford R, Griffin B, Newton R, Jackson G, Menon G, Harrison CJ, Israels T, Bailey S (2012) Burkitt's lymphoma. Lancet 379:1234-1244
3. Green M, Michaels MG (2013) Epstein-Barr virus infection and posttransplant lymphoproliferative disorder. Am J Transplant 13(Suppl 3):41-54

4. Cesarman E (2013) Pathology of lymphoma in HIV. Curr Opin Oncol 25:487-494

5. Hoshida Y, Xu JX, Fujita S, Nakamichi I, Ikeda J, Tomita Y, Nakatsuka S, Tamaru J, Iizuka A, Takeuchi T, Aozasa K (2007) Lymphoproliferative disorders in rheumatoid arthritis: clinicopathological analysis of 76 cases in relation to methotrexate medication. $\mathrm{J}$ Rheumatol 34:322-331

6. Miyoshi I, Kubonishi I, Yoshimoto S, Akagi T, Ohtsuki Y, Shiraishi Y, Nagata K, Hinuma Y (1981) Type C virus particles in a cord T-cell line derived by co-cultivating normal human cord leukocytes and human leukaemic T cells. Nature 294:770-771

7. Cesarman E, Chang Y, Moore PS, Said JW, Knowles DM (1995) Kaposi's sarcoma-associated herpesvirus-like DNA sequences in AIDS-related body-cavity-based lymphomas. N Engl J Med 332: 1186-1191

8. De Vita S, Sansonno D, Dolcetti R, Ferraccioli GF, Carbone A, Cornacchiulo V, Santini GF, Crovatto M, Gloghini A, Dammacco F, Boiocchi M (1995) Hepatitis C virus within a malignant lymphoma lesion in the course of type II mixed cryoglobulinemia. Blood 86: $1887-1892$

9. Shivapurkar N, Harada K, Reddy J, Scheuermann RH, Xu Y, McKenna RW, Milchgrub S, Kroft SH, Feng Z, Gazdar AF (2002) Presence of simian virus 40 DNA sequences in human lymphomas. Lancet 359:851-852

10. Roschewski M, Wilson WH (2012) EBV-associated lymphomas in adults. Best Pract Res Clin Haematol 25:75-89

11. Khan G, Norton AJ, Slavin G (1993) Epstein-Barr virus in Hodgkin disease. Relation to age and subtype. Cancer 71:3124-3129

12. Tomita Y, Ohsawa M, Kanno H, Hashimoto M, Ohnishi A, Nakanishi H, Aozasa K (1996) Epstein-Barr virus in Hodgkin's disease patients in Japan. Cancer 77:186-192

13. Harabuchi Y, Yamanaka N, Kataura A, Imai S, Kinoshita T, Mizuno F, Osato T (1990) Epstein-Barr virus in nasal T-cell lymphomas in patients with lethal midline granuloma. Lancet 335:128-130

14. Kanavaros P, Lescs MC, Brière J, Divine M, Galateau F, Joab I, Bosq J, Farcet JP, Reyes F, Gaulard P (1993) Nasal T-cell lymphoma: a clinicopathologic entity associated with peculiar phenotype and with Epstein-Barr virus. Blood 81:2688-2695

15. Ohsawa M, Nakatsuka S, Kanno H, Miwa H, Kojya S, Harabuchi Y, Yang WI, Aozasa K (1999) Immunophenotypic and genotypic characterization of nasal lymphoma with polymorphic reticulosis morphology. Int J Cancer 81:865-870

16. Nakatsuka S, Yao M, Hoshida Y, Yamamoto S, Iuchi K, Aozasa K (2002) Pyothorax-associated lymphoma: a review of 106 cases. J Clin Oncol 20:4255-4260

17. Aozasa K, Takakuwa T, Nakatsuka S (2005) Pyothorax-associated lymphoma: a lymphoma developing in chronic inflammation. Adv Anat Pathol 12:324-331

18. Fukayama M, Ibuka T, Hayashi Y, Ooba T, Koike M, Mizutani S (1993) Epstein-Barr virus in pyothorax-associated pleural lymphoma. Am J Pathol 143:1044-1049

19. Burkitt D (1958) A sarcoma involving the jaws in African children. Br J Surg 46:218-223

20. Swerdlow SH, Campo E, Harris NL, Jaffe ES, Pileri SA, Stein H, Thiele J, Vardiman JW (eds) (2008) WHO classification of tumours of haematopoietic and lymphoid tissues, 4th edn. IARC, Lyon

21. zur Hausen H, Schulte-Holthausen H, Klein G, Henle W, Henle G, Clifford P, Santesson L (1970) EBV DNA in biopsies of Burkitt tumours and anaplastic carcinomas of the nasopharynx. Nature 228: 1056-1058

22. Shibata D, Weiss LM (1992) Epstein-Barr virus-associated gastric adenocarcinoma. Am J Pathol 140:769-774 
23. Katsumura KR, Maruo S, Takada K (2012) EBV lytic infection enhances transformation of B-lymphocytes infected with EBV in the presence of T-lymphocytes. J Med Virol 84:504-510

24. Choy EY, Siu KL, Kok KH, Lung RW, Tsang CM, To KF, Kwong DL, Tsao SW, Jin DY (2008) An Epstein-Barr virus-encoded microRNA targets PUMA to promote host cell survival. J Exp Med 205:2551-2560

25. Vereide DT, Seto E, Chiu YF, Hayes M (2014) Epstein-Barr virus maintains lymphomas via its miRNAs. Oncogene 33:1258-1264

26. Xia T, O’Hara A, Araujo I, Barreto J, Carvalho E, Sapucaia JB, Ramos JC, Luz E, Pedroso C, Manrique M, Toomey NL, Brites C, Dittmer DP, Harrington WJ Jr (2008) EBV microRNAs in primary lymphomas and targeting of CXCL-11 by EBV-mir-BHRF1-3. Cancer Res 68:1436-1442

27. Fink SE, Gandhi MK, Nourse JP, Keane C, Jones K, Crooks P, Jöhrens K, Korfel A, Schmidt H, Neumann S, Tiede A, Jäger U, Dührsen U, Neuhaus R, Dreyling M, Borchert K, Südhoff T, Riess H, Anagnostopoulos I, Trappe RU (2014) A comprehensive analysis of the cellular and EBV-specific microRNAome in primary CNS PTLD identifies different patterns among EBV-associated tumors. Am J Transplant 14:2577-2587

28. Leoncini L, Raphael M, Stein H, Harris NL, Jaffe ES, Kluin PM (2008) Burkitt lyphoma. In: Swerdlow SH, Campo E, Harris NL, Jaffe ES, Pileri SA, Stein H, Thiele J, Vardiman JW (eds) WHO classification of tumours of haematopoietic and lymphoid tissues, 4th edn. IARC, Lyon

29. Rochford R, Cannon MJ, Moormann AM (2005) Endemic Burkitt's lymphoma: a polymicrobial disease? Nat Rev Microbiol 3:182-187

30. Donati D, Zhang LP, Chêne A, Chen Q, Flick K, Nyström M, Wahlgren M, Bejarano MT (2004) Identification of a polyclonal Bcell activator in Plasmodium falciparum. Infect Immun 72:54125418

31. Bernasconi NL, Onai N, Lanzavecchia A (2003) A role for Toll-like receptors in acquired immunity: up-regulation of TLR9 by BCR triggering in naive $\mathrm{B}$ cells and constitutive expression in memory B cells. Blood 101:4500-4504

32. Gutensohn N, Cole P (1980) Epidemiology of Hodgkin's disease. Semin Oncol 7:92-102

33. Mueller N, Evans A, Harris NL, Comstock GW, Jellum E, Magnus K, Orentreich N, Polk BF, Vogelman J (1989) Hodgkin's disease and Epstein-Barr virus. Altered antibody pattern before diagnosis. N Engl J Med 320:689-695

34. Anagnostopoulos I, Hansmann ML, Franssila K, Harris M, Harris NL, Jaffe ES, Han J, van Krieken JM, Poppema S, Marafioti T, Franklin J, Sextro M, Diehl V, Stein H (2000) European Task Force on Lymphoma project on lymphocyte predominance Hodgkin disease: histologic and immunohistologic analysis of submitted cases reveals 2 types of Hodgkin disease with a nodular growth pattern and abundant lymphocytes. Blood 96:1889-1899

35. Weiss LM, Movahed LA, Warnke RA, Sklar J (1989) Detection of Epstein-Barr viral genomes in Reed-Sternberg cells of Hodgkin's disease. N Engl J Med 320:502-506

36. Anagnostopoulos I, Herbst H, Niedobitek G, Stein H (1989) Demonstration of monoclonal EBV genomes in Hodgkin's disease and $\mathrm{Ki}-1$-positive anaplastic large cell lymphoma by combined Southern blot and in situ hybridization. Blood 74:810-816

37. Herling M, Rassidakis GZ, Jones D, Schmitt-Graeff A, Sarris AH, Medeiros LJ (2004) Absence of Epstein-Barr virus in anaplastic large cell lymphoma: a study of 64 cases classified according to World Health Organization criteria. Hum Pathol 35:455-459

38. Cazals-Hatem D, Lepage E, Brice P, Ferrant A, d'Agay MF, Baumelou E, Brière J, Blanc M, Gaulard P, Biron P, Schlaifer D, Diebold J, Audouin J (1996) Primary mediastinal large B-cell lymphoma. A clinicopathologic study of 141 cases compared with 916 nonmediastinal large B-cell lymphomas, a GELA ("Groupe d'Etude des Lymphomes de l'Adulte") study. Am J Surg Pathol 20:877-888
39. Jaffe ES, Stein H, Swerdlow SH, Campo E, Pileri SA, Harris NL (2008) B-cell lymphoma, unclassifiable, with features intermediate between diffuse large B-cell lymphoma and classical Hodgkin lyphoma. In: Swerdlow SH, Campo E, Harris NL, Jaffe ES, Pileri SA, Stein H, Thiele J, Vardiman JW (eds) WHO classification of tumours of haematopoietic and lymphoid tissues, 4th edn. IARC, Lyon

40. Iuchi K, Ichimiya A, Akashi A, Mizuta T, Lee YE, Tada H, Mori T, Sawamura K, Lee YS, Furuse K, Yamamoto S, Aozasa K (1987) Non-Hodgkin's lymphoma of the pleural cavity developing from long-standing pyothorax. Cancer 60:1771-1775

41. Ng CS, Chan JK, Lo ST (1987) Expression of natural killer cell markers in non-Hodgkin's lymphomas. Hum Pathol 18:1257-1262

42. Ng CS, Chan JK, Hui PK, Chan WC, Lo ST (1988) Application of a $\mathrm{T}$ cell receptor antibody beta $\mathrm{F} 1$ for immunophenotypic analysis of malignant lymphomas. Am J Pathol 132:365-371

43. Aozasa K, Ohsawa M, Tajima K, Sasaki R, Maeda H, Matsunaga T, Friedmann I (1989) Nation-wide study of lethal mid-line granuloma in Japan: frequencies of Wegener's granulomatosis, polymorphic reticulosis, malignant lymphoma and other related conditions. Int $\mathrm{J}$ Cancer 44:63-66

44. Delecluse HJ, Anagnostopoulos I, Dallenbach F, Hummel M, Marafioti T, Schneider U, Huhn D, Schmidt-Westhausen A, Reichart PA, Gross U, Stein H (1997) Plasmablastic lymphomas of the oral cavity: a new entity associated with the human immunodeficiency virus infection. Blood 89:1413-1420

45. Stein H, Harris NL, Campo E (2008) Plasmablastic lyphoma. In: Swerdlow SH, Campo E, Harris NL, Jaffe ES, Pileri SA, Stein H, Thiele J, Vardiman JW (eds) WHO classification of tumours of haematopoietic and lymphoid tissues, 4th edn. IARC, Lyon

46. Thakral C, Thomas L, Gajra A, Hutchison RE, Ravizzini GC, Vajpayee N (2009) Plasmablastic lymphoma in an immunocompetent patient. J Clin Oncol 27:e78-e81

47. Morscio J, Dierickx D, Nijs J, Verhoef G, Bittoun E, Vanoeteren X, Wlodarska I, Sagaert X, Tousseyn T (2014) Clinicopathologic comparison of plasmablastic lymphoma in HIV-positive, immunocompetent, and posttransplant patients: single-center series of 25 cases and meta-analysis of 277 reported cases. Am J Surg Pathol 38:875-886

48. Rowe DT, Webber S, Schauer EM, Reyes J, Green M (2001) EpsteinBarr virus load monitoring: its role in the prevention and management of post-transplant lymphoproliferative disease. Transpl Infect Dis 3: 79-87

49. Guinee D Jr, Jaffe E, Kingma D, Fishback N, Wallberg K, Krishnan J, Frizzera G, Travis W, Koss M (1994) Pulmonary lymphomatoid granulomatosis. Evidence for a proliferation of Epstein-Barr virus infected B-lymphocytes with a prominent T-cell component and vasculitis. Am J Surg Pathol 18:753-764

50. Wada N, Ikeda J, Hori Y, Fujita S, Ogawa H, Soma T, Sugiyama H, Fukuhara S, Kanamaru A, Hino M, Kanakura Y, Morii E, Aozasa K (2011) Epstein-barr virus in diffuse large B-Cell lymphoma in immunocompetent patients in Japan is as low as in western countries. J Med Virol 83:317-321

51. Abruzzo LV, Schmidt K, Weiss LM, Jaffe ES, Medeiros LJ, Sander CA, Raffeld M (1993) B-cell lymphoma after angioimmunoblastic lymphadenopathy: a case with oligoclonal gene rearrangements associated with Epstein-Barr virus. Blood 82:241-246

52. Zettl A, Lee SS, Rüdiger T, Starostik P, Marino M, Kirchner T, Ott M, Müller-Hermelink HK, Ott G (2002) Epstein-Barr virus-associated B-cell lymphoproliferative disorders in angloimmunoblastic T-cell lymphoma and peripheral T-cell lymphoma, unspecified. Am J Clin Pathol 117:368-379

53. Zaki MA, Wada N, Kohara M, Ikeda J, Hori Y, Fujita S, Ogawa H, Sugiyama H, Hino M, Kanakura Y, Morii E, Aozasa K (2011) Presence of B-cell clones in T-cell lymphoma. Eur J Haematol 86: $412-419$ 
54. Attygalle AD, Chuang SS, Diss TC, Du MQ, Isaacson PG, Dogan A (2007) Distinguishing angioimmunoblastic T-cell lymphoma from peripheral T-cell lymphoma, unspecified, using morphology, immunophenotype and molecular genetics. Histopathology 50:498508
55. Tan BT, Warnke RA, Arber DA (2006) The frequency of B- and Tcell gene rearrangements and epstein-barr virus in T-cell lymphomas: a comparison between angioimmunoblastic T-cell lymphoma and peripheral T-cell lymphoma, unspecified with and without associated B-cell proliferations. J Mol Diagn 8:466-475 